\title{
Supply Chain Management and Logistics Big Data Challenges in Bulgaria
}

\author{
Nikolay Dragomirov $^{1 *}$ and Luben Boyanov ${ }^{2}$ \\ ${ }^{1}$ University of National and World Economy, Department of Logistics and Supply Chains, Sofia, \\ Bulgaria; Email: ndragomirov@unwe.bg \\ ${ }^{2}$ University of National and World Economy, Department of Information Technologies and \\ Communications, Sofia, Bulgaria; Email: lboyanov@unwe.bg
}

\section{*Corresponding Author: Nikolay Dragomirov}

Received: 3 March 2021; Revised: 23 April 2021; Accepted: 5 October; Published: 11 November 2021

\begin{abstract}
The article focuses on the challenges of applying big data approaches to logistics and supply chain management in Bulgaria, while also presenting the challenges, opportunities and problems from a broader perspective. This includes a review of big data in logistics and its subsystems in relation to integration and transformation processes, as well as the role of big data and the relevant technologies in supply chain management. The research framework for the study of Bulgarian companies focuses on their experiences, both positive and negative, with big data. Data was collected using an electronic questionnaire. The respondents were from small, medium-sized and large companies alike. The results demonstrate and explain the companies' experiences with big data and the level of application thereof. The findings showed that the main areas for the use of big data are order processing, communication processes, reporting systems, inventory management and vehicle database management.
\end{abstract}

Keywords: Logistics, SCM, big data

\section{List of Abbreviations:}

- Artificial Intelligence (AI)

- Customer relationship management (CRM)

- Enterprise resource planning (ERP) system

- Human resources (HR)

- Information Technologies (IT)

- Internet of Things (IoT)

- Machine-to-machine (M2M) communication

- Supplier relationship management (SRM)

- Supply chain management (SCM)

- Transport management system (TMS) 
- Virtual and augmented realities (VA and AR)

- Warehouse management system (WMS)

\section{Introduction}

Big data is a rapidly expanding area of research and involves the application of information technologies (IT) for the collection, storage, processing and analysis of data that are too complex and/or big for traditional computer systems. Big data is generated from variety of different sources in almost any area of human activities [1]. The phenomenon that is big data is expected to (and is already doing so) bring new knowledge, models and approaches to every aspect of human activity. This can be seen as a new revolution in IT, one that will change the way people work and live. This topic is a considerable research area with growing attention [2]. It also is predicted to have great value, it is expected to generate big market size in the future, carrying big challenges with it [3].

The great challenges of big data are the acquisition, storage, search, sharing, analysis and visualization thereof. When talking about big data, reference is made to the three $\mathrm{V}^{\prime} \mathrm{s}$ (V3), or the four V's (V4), five V's (V5), seven V's (V7), etc. Volume, variety and velocity are the most famous $\mathrm{V}^{\prime}$ s, with veracity, value, variability and visualization following closely behind. There are many sources of big data - web pages, social networks, financial records and scientific data. However, one of the most important and constantly expanding sources of data is the Internet of Things (IoT) [4]. This represents another dynamic development in the field of IT, one that has penetrated almost every field of human activity. Sensors and digital identifiers are now part of our home, office, banking, transportation, environment, city, factories, clothes, etc. Storing big data requires storage volumes that are thousands or millions of times larger than a traditional computer or server can provide. This is reflected in the need for new approaches and structures to the storage and retrieval of such large volumes of data [5]. If the aforementioned can be successfully implemented, the greatest benefit to people will be the final goal of big data, namely data analysis. So far, people and traditional computing devices have been unable (or in a limited number of cases) to extract important and meaningful links, relationships and correlations in data that have encompassed some, or just limited, areas of human and industrial activities. Although there have been numerous attempts to apply various analytical approaches to data science applications, there remains much more to be achieved in the near future [6]. The reason for this is the continuing digitalization of our society (the spread and universal use of computers, Internet access, digital mobile phones, digital identifiers, etc.), which until two decades ago, was narrow in scope. Nowadays, with IoT, Internet, mobile phones and their use in every aspect of human activity all over the world, those limitations have vanished. Digital has become global and very big, as has the volume of associated data that is created, recorded, distributed, stored and processed. Also appearance of large-scale service oriented systems generate bug data [7]. As a result, 
this has given rise to opportunities to use data to the benefit of every field of human and societal activity.

Around the world, big IT companies have rushed to develop and offer big data processing platforms and approaches. The most popular are Amazon's AWS, Microsoft Azure, Cloudera's Enterprise Bigdata, IBM Big Data, Google Bigdata, Oracle Bigdata Analytics, Hortonworks Data Platform, Intel Bigdata, to name but a few. These platforms use their clouds, which include both proprietary and popular open source software packets, such as those of the Apache Software foundation [8] - to name few - Hadoop, Kafka, Spark, Hive, Impala, Flink, Kudu, Storm and others.

\section{Big Data in Logistics}

Logistics is a complex and dynamic activity that can create a large amount of data. It can be significantly optimised and made more efficient when using big data and the opportunities offered by it. In logistics, the data sources are numerous due to the link between logistics and the flow of materials. The activities also relate to the actual physical environment and its diversity and unpredictability. The most obvious and logical source of data in an organisation is its IT systems. These can include, individually or combined, systems for enterprise resource planning (ERP), warehouse management (WMS), transport management (TMS), customer relationship management (CRM), supplier relationship management (SRM), human resources (HR), etc. They all generate data that accumulates over time. In addition, data can come from the website of an organisation, social networks, market trends, international prices of commodities, etc. In other words, big data is constantly being created, both in terms of quantity and quality. Within the context of these new parameters, analysis by traditional digital means is almost impossible. Most conventional software systems cannot easily cope with the volumes and diversity of big data. Consequently, in order to study and develop this new source of knowledge, it is necessary to integrate data into a compatible (for all products and software packages) big data platform. It is only by applying such an approach that the data can ultimately be analysed. Using big data and IoT can reveal some of the bottlenecks in traditional supply chain management, (SCM), WMS, CRM, SRM and other related areas. Big Data is useful for the business in the areas of logistics and supply chain management [9] and it is important element from Logistics 4.0 [10]. To achieve this, these systems will need to be optimised and significantly improved in order to work with the new volumes and diversity of data. This transformation and integration process is shown in Figure 1. 


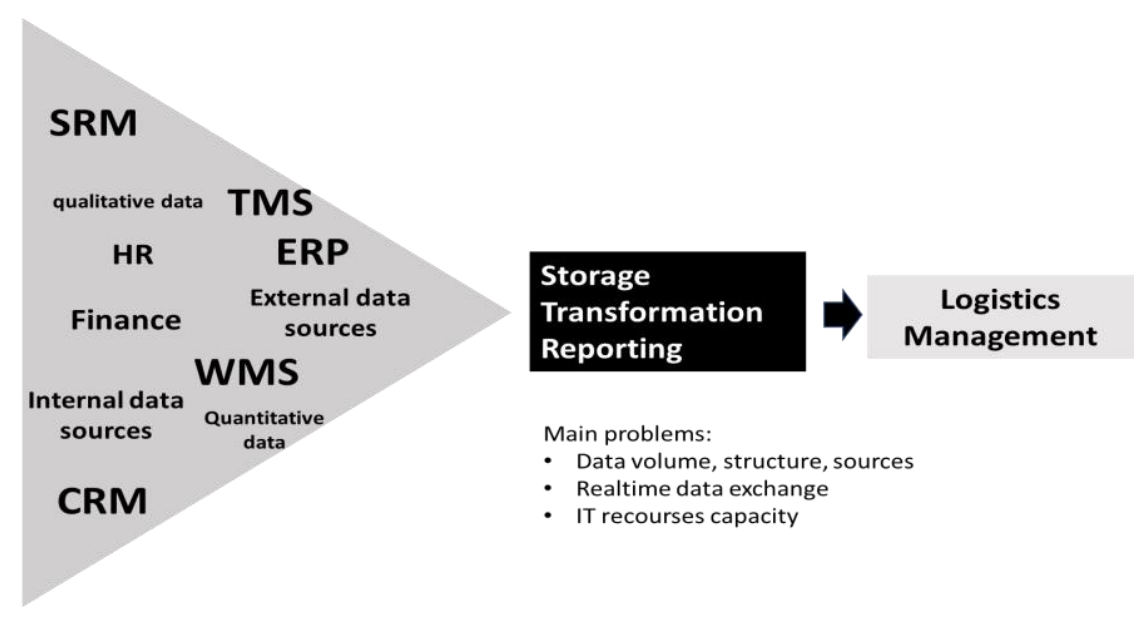

Fig. 1. Big data transformation process in logistics. Source: [11]

Nowadays, the large quantities of data generated by sources such as ERP, manufacturing, orders, shipping, social media and other systems is being added to in the form of GPS signals (position tracking), RFID (tag detection) identifiers, video, etc. This also does not exclude data generated by less notable technologies, tools and systems that form input for the IT world. Even the data flow between the insurer and the customer is related to big data adaptation [12]. Combined, they aim to improve the work and performance of supply chains, thereby leading to better decision-making, reduced administrative costs and improved customer satisfaction. For example, some organisations use big data to optimise waste minimisation in food supply chains [13], others use it to improve planning in logistics, production, and scheduling [14], or to reduce the carbon footprint of a supply chain [15]. There are also cases where the efficiency of logistics activities can be improved through the application of sensor data-based predictive maintenance [16], or by implementing predictive analysis and demand management [17]. More examples of big data applications in logistics can be found in [18].

The main objective of logistics is to ensure the movement of material flows in the supply chains - starting with unprocessed raw materials and ending with the end customer using the finished products. CSCMP state that the supply chain links many companies together [19]. It is, in essence, a system involving many organisations linked together, whereby they all function to ensure the movement of material flows from their place of origin to the place of consumption. This system consists of different subsystems, the most important being warehousing and transportation. They are part of the basis for logistics systems [20] and are of particular interest for several reasons.

By summarising popular theoretical concepts and practice, and in accordance with the stages of material flows in the supply chain, the following subsystems can be identified:

- Supplier relationship management;

- Manufacturing execution systems;

- Customer relationship management. 
Another popular classification according to different logistics activities identifies the following groups:

- $\quad$ Transport management systems (TMS);

- Warehouse management system (WMS).

Nowadays, it is very popular for companies to use ERP software, which enables the better control and planning of resources. ERP systems integrate a company's functional departments (logistics/operations, marketing, HR and finance). In practice, they can also partially cover the functions of some other systems - CRM, SRM, TMS, WMS - or fully integrate them [21]. The earliest platforms focused on accounting and basic inventory management. Later, other sectors were incorporated, including mobile applications and electronic commerce in recent years. Today, it is not only large and medium-sized companies that use ERP, but also small ones, which is indicative of its increasing importance for business in the control and monitoring of a company's entire chain of activities. Over time, ERP systems have become more flexible and modular and are now even available in cloud-based forms or as a SaaS (Software as a Service) model on a subscription basis.

When analysing the logistics management, it is necessary to mention supply chain management trends. In the supply chain, value added is the result of synergies among firms that comprise the supply chain. These synergies relate to five critical flows: information, product, service, finance and knowledge [22, p.6]. [23] defines that 'The way in which entities in a supply chain become connected is through shared information'. The conclusion is that material flows are managed by information and that is why data and information are so important for logistics. SCM is 'The management of upstream and downstream relationships with suppliers and customers in order to deliver superior customer value at less cost to the supply chain as a whole' [23]. For this, information systems are critical. SCM is currently seeing significant technological improvements through modern digital transformation [24]. The digitalization process of logistics systems is a complex problem [25] and it is challenging. More and more often new digital technologies are being applied to activities. Technological factors like IoT, blockchain, machine-to-machine (M2M) communication, artificial intelligence (AI), virtual and augmented realities (VA and AR) are being used, or are being planned to be used by many companies in the near future. In the short- to mid-term, improvements in the efficacy and modernisation of SCM will therefore come from the digitalization and digital transformation processes. However, whilst bearing this in mind, it is also important to recognise that methodologies and strategies also continue to play key roles.

\section{Research Framework}

The findings of the research are based on the results of a questionnaire survey into the logistics activities of different Bulgarian companies - trade, manufacturing and logistics service providers. 
The aim was to assess the key problems related to the digital transformation of the logistics management, including some big data problems and perspectives. The formulated questions for the collection of data on the usage of different systems had to be assessed by respondents according to a 5-point Likert scale (1 - Strongly disagree, 2 - Somewhat disagree, 3 - Neither agree nor disagree, 4 - Somewhat agree, 5 - Strongly agree). This approach is common for the evaluation of the implementation of different practices. This article covers big data problems and perspectives by examining the answers to different questions about the degree of usage of the following logistics subsystems:

- Supplier relationship management;

- Customer relationship management;

- Transport management systems;

- Warehouse management systems;

- Enterprise resource planning systems.

The averages of the results (answers) were calculated and then sorted, and the first quartiles subsequently selected for each group. From the selections, the main areas that could be potential sources of problems and challenges for SCM and big data issues within the logistics activities management in Bulgaria were identified.

\section{Data Collection}

The survey was conducted among companies in Bulgaria. Representatives of the participating companies were asked to complete an electronic questionnaire. The collected data concerned CRM, SRM, ERP, TMS and WMS systems. The results were divided into three major groups: 1) CRM and SRM; 2) ERP; and 3) TMS and WMS. The areas of use of the systems were identified according to their specificity.

\section{Main Findings and Discussion}

The number of respondents was approximately 150, with $54 \%$ from small companies (up to 49 employees), $27 \%$ from medium-sized companies (50 - 249 employees), and 19\% from large companies (over 250 employees). In terms of ownership, 20\% of companies operating in Bulgaria are foreign owned, with the remaining $80 \%$ being entirely Bulgarian. In the sample, different companies involved in the management of material flows in the supply chain were included.

For the processing of the answers to the questions about the main purpose of the various systems in the organisation, a number of activities were selected. For Group 1 this concerned data on the customer service and supplier relationship management systems. The data are presented in Table 1, 
with the activities sorted in descending order, i.e. those activities with the highest mean values are at the top.

Table 1 Usage of CRM and SRM systems. Source: authors

\begin{tabular}{|c|c|c|c|}
\hline CRM & & SRM & \\
\hline Receiving orders & 4.21 & Document management & 3.87 \\
\hline Maintaining a customer database & 4.20 & Maintaining a database of suppliers & 3.63 \\
\hline Communication with customers & 4.15 & Communication with the warehouse & 3.58 \\
\hline Order status management & 4.09 & Communication with suppliers & 3.54 \\
\hline Accepting complaints & 3.92 & Communication with transporter/courier & 3.53 \\
\hline Preparation of offers & 3.84 & $\begin{array}{l}\text { Synchronisation of employees responsible for } \\
\text { deliveries }\end{array}$ & 3.45 \\
\hline Communication with transporter/courier & 3.81 & Receiving offers & 3.36 \\
\hline Communication with the warehouse & 3.81 & Negotiating with suppliers & 3.35 \\
\hline $\begin{array}{l}\text { Synchronisation of employees responsible for } \\
\text { customers }\end{array}$ & 3.76 & Online auctions & 2.33 \\
\hline Employee management (sales) & 3.62 & & \\
\hline Sending congratulatory and reminder messages & 3.46 & & \\
\hline
\end{tabular}

For CRM systems, it is possible to state that the following are the top quartile activities: receiving orders, maintaining a customer database, communication with customers, and management/tracking of order status. For the other systems, the top activities are document management, maintaining a database with suppliers, and communication with the warehouse. Unfortunately, both the CRM and SRM systems are also used for basic tasks, mainly for communication and database management.

The results from identical questions asked about the companies' enterprise resource planning (ERP) systems are presented in Table 2. Here, it is possible to conclude that ERP systems are involved in several areas of logistics, such as warehousing, order processing, accounting and finance. Although the interaction with the other members of the supply chain is relatively low at present, that may change in the future with the appearance of more supply chain management practices.

Table 2 Usage of ERP systems. Source: authors

\begin{tabular}{ll}
\hline Warehouse process management & 3.89 \\
\hline Order processing & 3.88 \\
\hline Inventory management & 3.83 \\
\hline Customer service management & 3.68 \\
\hline Interaction of logistics and accounting / finance departments & 3.67 \\
\hline Transport process management & 3.65 \\
\hline Interaction of the marketing and logistics departments & 3.53 \\
\hline Management of work (daily work) with suppliers & 3.51 \\
\hline Demand forecasting & 3.43 \\
\hline Interaction of logistics and production departments & 3.34 \\
\hline Interaction of logistics and human resources departments & 3.16 \\
\hline
\end{tabular}


Demand forecasting is a specific issue. Unfortunately, most of the systems offer no way of applying different quantitative methods for forecasting. Instead, they are used as a reporting system, which leads to the (over)simplification of data structures.

The last group concerns direct logistics activities. The data for TMS and WMS systems are presented in Table 3.

Table 3 Usage of TMS and WMS systems. Source: authors

\begin{tabular}{lclc}
\hline \multicolumn{1}{c}{ TMS } & \multicolumn{2}{c}{ WMS } \\
\hline Reporting & $\mathbf{3 . 8 5}$ & Invoice issuing & 3.96 \\
\hline $\begin{array}{l}\text { Database for transport } \\
\text { tasks }\end{array}$ & $\mathbf{3 . 7 8}$ & Receiving orders & 3.77 \\
\hline Distribution of routes & 3.53 & Order processing & 3.66 \\
\hline Vehicle database & 3.53 & Inventory management & 3.55 \\
\hline $\begin{array}{l}\text { Synchronisation between } \\
\text { vehicles and delivery } \\
\text { points }\end{array}$ & 3.52 & Labelling & 3.39 \\
\hline $\begin{array}{l}\text { Customer relationship } \\
\text { management }\end{array}$ & 3.45 & Storage location & \\
\hline Database of drivers & 3.35 & management & 3.30 \\
\hline Offer preparation & 3.24 & Picking orders & 3.16 \\
\hline & & Packing & 3.05 \\
\hline & & Demand forecasting & 3.04 \\
\hline
\end{tabular}

On the basis of an analysis of the results, the authors accept the validity of some of the findings for the CRM and SRM systems. It is also clear that the TMS and WMS systems are used to deal with traditional problems only, which does not lead to the generation of big data. In addition, the integration of with other systems and the use of different IT solutions seems relatively low. In the modern transport systems big data systems are being used for routing, fuelling, vehicles maintenance and etc. [26]. The aforementioned could be researched in more detail in another study, however, the main hypotheses are centred around the type of competition in Bulgaria and the overall vision for doing business.

Nevertheless, the research data show that primary logistics activities offer a higher potential for including big data problems. Within this context, the main areas for big data relate to:

1. Order processing and tracking;

2. Communication;

3. Reporting;

4. Maintaining master data and reporting actives for inventory management;

5. Databases for vehicles and their daily activities.

Most of the areas can be defined as traditional, i.e. conventional use of information systems in logistics and SCM. This reveals that there are a multitude of opportunities for implementing modern methods of data and information management that would lead to the more efficient management of material flows in the supply chain. One way to achieve this is by raising awareness of modern IT 
solutions and the use of big data infrastructures, such as cloud systems (typically on a pay-per-use basis) or centres of excellence or competence, which already exist or are in the process of being established [17].

\section{Conclusions}

The results of the research presented in this article reveal only some of the major big data problems in logistics and supply chain management in Bulgaria. The overall results were as expected and in line with previous research findings [11] with regards to the influence and use of big data in logistics. Unfortunately, the expectations regarding the future use of big data in Bulgaria is relatively poor. This is due to the low level of integration of information systems within organisations and supply chains, as well as the inadequate use of modern information technologies. It should be noted that the main challenges facing CRM and SRM systems are centred around receiving orders, managing documents, maintaining a customer/supplier database, as well as database maintenance and some communication issues. Unfortunately, the problems are primarily related to order management instead of the management of logistics processes. This is due to the relatively low use of information systems and technologies in logistics and in supply chain management. Through their responses, the respondents indicated that their focus is more on obvious problems. Consequently, the overall performance of logistics is not adequately covered. It can be assumed that this issue will be addressed in the near future, thereby giving room for continued research into the results of the change process and the dynamics thereof.

\section{References}

[1] George, G., Haas, M.R. \& Pentland A. (2014). Big Data and Management. AMJ 57(2), 321326. DOI: $10.5465 / \mathrm{amj} .2014 .4002$.

[2] Yaqoob, I., Abaker, I., Hashem, T., Gani, A., Mokhtar, S., Ahmed, E., Anuar, N.B., Athanasios V. \& Vasilakos, E. (2016). Big Data: From Beginning to Future. International Journal of Information Management 36(6), 1231-1247. DOI: 10.1016/j.ijinfomgt.2016.07.009.

[3] Jin, X., Wah, B.W., Cheng, X. \& Wang, Y. (2015). Significance and Challenges of Big Data Research. Big Data Research 2(2), 59-64. DOI: 10.1016/j.bdr.2015.01.006.

[4] Ge, M., Bangui, H. \& Buhnova, B. (2018). Big Data for Internet of Things: A Survey. Future Generation Computer Systems 87, 601-614. DOI: 10.1016/j.future.2018.04.053.

[5] Siddiqa, A., Karim, A. \& Gani, A. (2017). Big Data Storage Technologies: a Survey. In Frontiers Inf Technol Electronic Eng. 18(8), 1040-1070. DOI: 10.1631/FITEE.1500441. 
[6] Milev, P. (2020, July). Conceptual Approach for Application of Data Science in Web Analytics. Proceedings of International conference on application of information and communication technology and statistics in economy and education (ICAICTSEE - 2019) 229-234. Retrieved on July 05, 2021 from http://icaictsee.unwe.bg/past-conferences/ICAICTSEE-2019.pdf

[7] Zheng, Z., Zhu, J. \& Lyu, M.R. (2013). Service-Generated Big Data and Big Data-as-a-Service: An Overview In 2013 IEEE International Congress on Big Data, Santa Clara, CA, USA, Jun. 2013, 403-410. DOI: 10.1109/BigData.Congress.2013.60.

[8] Apache Foundation (2021, July). The Apache Software Foundation. Welcome to The Apache Software Foundation. Retrieved May 03, 2021, retrieved July 09, 2021 from https://apache.org

[9] Ghosh, D. (2015) Big Data in Logistics and Supply Chain management - a Rethinking Step. In 2015 International Symposium on Advanced Computing and Communication (ISACC), Silchar, India, Sep. 2015, 168-173. DOI: 10.1109/ISACC.2015.7377336.

[10] Winkelhaus, S \& Grosse, E.H. (2020). Logistics 4.0: a Systematic Review Towards a New Logistics System. International Journal of Production Research 58(1), 18-43. DOI: 10.1080/00207543.2019.1612964.

[11] Dragomirov, N. (2015). Big Data in Logistics - Definition and Sources, Vanguard Scientific Instruments in Management 11(2). ISSN 1314-0582.

[12] Chaba, R. (2021). Influence of Telematics of Ubi Insurance on the Management of the Fleet of Company Vehicles. The Archives of Automotive Engineering - Archiwum Motoryzacji 69-82, 2084-476X. DOI: 10.14669/AM.VOL92.ART5.

[13] Mishra, N. \& Singh, A. (2018). Use of Twitter Data for Waste Minimisation in Beef Supply Chain. Ann Oper Res 270(1-2), 337-359. DOI: 10.1007/s10479-016-2303-4.

[14] Zhong, R.Y., Newman, S.T., Huang, G.Q. \& Lan, S. (2016). Big Data for Supply Chain Management in the Service and Manufacturing Sectors: Challenges, Opportunities, and Future perspectives. Computers \& Industrial Engineering 101572-101591. DOI: 10.1016/j.cie.2016.07.013

[15] Singh, A., Mishra, N., Ali, S.I., Shukla, N. \& Shankar, R. (2015). Cloud Computing Technology: Reducing Carbon Footprint in Beef Supply Chain. International Journal of Production Economics 164462-164471. DOI: 10.1016/j.ijpe.2014.09.019.

[16] Govindan, K., Soleimani, H. \& Kannan, D. (2015). Reverse Logistics and Closed-loop Supply Chain: A Comprehensive Review to Explore the Future. European Journal of Operational Research 240(3), 603-626. DOI: 10.1016/j.ejor.2014.07.012. 
[17] Schoenherr, C. \& Speier-Pero, D. (2015). Data Science, Predictive Analytics, and Big Data in Supply Chain Management: Current State and Future Potential. Journal of Business Logistics 36(1), 120-132. DOI: https://doi.org/10.1111/jbl.12082.

[18] Govindan, K., Cheng, T.C.E., Mishra, N. \& Shukla, C. (2018). Big data analytics and application for logistics and supply chain management. Transportation Research Part E: Logistics and Transportation Review 114. DOI: 10.1016/j.tre.2018.03.011.

[19] CSCMP.org, (2013). Supply chain Management Terms and Glossary. Retrieved May, 20, 2020, from https://cscmp.org/CSCMP/Educate/SCM_Definitions_and_Glossary_of_Terms/CSCMP/Educ ate/SCM_Definitions_and_Glossary_of_Terms.aspx

[20] Ballou, R.H. (1992). Business Logistics Management, 3rd ed. Englewood Cliffs, N.J: Prentice Hall, 1992. ISBN 9780131055452.

[21] Dragomirov, N. (2015). Information Systems and Technologies. Sofia: Publishing Complex UNWE (in Bulgarian). Retrieved October 06, 2021, from https://www.unwe.bg/uploads/Alternatives/6-Dragomirov.pdf

[22] Bowersox, D.J., Closs, M. \& Cooper, B. (2002). Supply Chain Logistics Management. McGraw-Hill, 2002. ISBN 007112306-7.

[23] Christopher, M. (2011). Logistics \& Supply Chain Management, 4. ed. Harlow: Financial Times Prentice Hall. DOI: 10.1016/j.pursup.2014.05.001.

[24] Boyanov, L. (2019). Perspectives and approaches in the digital transformation of Supply chain management. Proceedings of the 1st Scientific and Business Conference on Logistics and Supply Chain Management, University of National and World Economy 116-126. Retrieved July 16, 2021, from https://www.researchgate.net/publication/342637657

[25] Demirova, S. (2019). Fundamental nature of logistic processes and opportunities to digitalization. Innovations 7(1), 21-24. ISSN 1314-8907.

[26] Hopkins, J. \& Hawking, P. (2018). Big Data Analytics and IoT in logistics: a case study. IJLM 29(2), 575-591. DOI: 10.1108/IJLM-05-2017-0109. 